ISSN: $1130-3743$

\title{
TH. W. ADORNO: APORTACIONES PARA UNA TEORÍA CRÍTICA DE LA EDUCACIÓN
}

\author{
Th. W. Adorno: contributions for a critical theory \\ of the education
}

\section{Th. W. Adorno: apports pour une théorie critique de l'éducation}

José A. Zamora

Instituto de Filosofía, Centro de Ciencias Humanas y Sociales. Consejo Superior de Investigaciones Científicas. Albasanz, 26-28. 28037 Madrid. Correo-e: joseantonio. zamora@cchs.csic.es

Fecha de recepción: enero de 2009

Fecha de aceptación definitiva: abril de 2009

Biblid [(1130-3743) 21, 1, 2009, 19-48]

RESUMEN

Este artículo pretende presentar los elementos más significativos del pensamiento filosófico de Th. W. Adorno para una teoría crítica de la educación. Desde una posición marginal respecto a la disciplina, sus reflexiones sobre el papel de la educación en el contexto de la crisis de la modernidad, recogidas en una serie de artículos y en varias entrevistas para la radio, merecen ser analizadas y valoradas en el contexto actual. En especial merecen atención sus tesis sobre la sociedad antagonista y la casi total integración de los individuos debilitados, su teoría del vuelco dialéctico de la cultura burguesa del espíritu en industria cultural, así como la transformación del ideal burgués de formación (Bildung) en pseudoformación (Halbbildung). Por último, prolongamos y actualizamos algunas de sus intuiciones sobre la supeditación de la formación profesional (Ausbildung) a la lógica totalizadora del mercado que suele encubrirse bajo el término ideológico de "sociedad del conocimiento". 
Palabras clave: dominación social, sociedad antagonista, integración coactiva, cultura burguesa, industria cultural, formación (Bildung), pseudoformación (Halbbildung), sociedad del conocimiento.

SUMMARY

This article intends to present the most significant elements of the philosophical thought of Th. W. Adorno for a critical theory of the education. From a marginal position in relation to the academic subject, his reflections on the role of the education in the context of the crisis of the modernity, collected in a series of articles and in several interviews for the radio, deserve to be analyzed and valued in the current context. Especially deserve attention his theses on the antagonistic society and the almost total integration of the weakened individuals, his theory of the dialectic turn of the bourgeois culture of the spirit in cultural industry, as well as the transformation of the bourgeois ideal of formation (Bildung) in pseudoformation (Halbbildung). Finally we prolong and update some of his intuitions on the subordination of the professional education (Ausbildung) to the totalizing logic of the market that usually hides under the ideological term of "society of the knowledge".

Key words: social domination, antagonistic society, coercive integration, bourgeois culture, cultural industry, formation (Bildung), pseudo-formation (Halbbildung), society of the knowledge.

\section{SOMMAIRE}

Cet article essaie de présenter les éléments les plus significatifs de la pensée philosophique de Th. W. Adorno pour une théorie critique de l'éducation. Depuis une position marginale par rapport à la discipline, ses réflexions sur le rôle de l'éducation dans le contexte de la crise de la modernité, réunies dans une série d'articles et en différents entretiens pour la radio, méritent être analysées et évaluées dans le contexte actuel. Spécialement méritent attention sa thèse sur la société antagoniste et la presque totale intégration des individus affaiblis, sa théorie du tournant dialectique de la culture bourgeoise de l'esprit en industrie culturelle, ainsi que la transformation de l'idéal bourgeois de formation (Bildung), en pseudo-formation (Halbbildung). Finalement nous prolongeons et actualisons quelques-unes de ses intuitions sur la subordination de la formation professionnelle (Ausbildung) à la logique totalisatrice du marché qu'il se cache sous le terme idéologique de "société de la connaissance".

Mots clés: domination sociale, société antagoniste, intégration coercitive, culture bourgeoise, industrie culturelle, formation (Bildung), pseudo-formation (Halbbildung), société de la connaissance. 
Para caracterizar la situación pedagógica actual Th. W. Adorno usó una expresión que no ha tenido especial acogida en las teorías de la educación más influyentes. Él habló de "educación después de Auschwitz". Naturalmente dicha expresión pretende reflejar algo más que un dato cronológico. Expresa una exigencia radical que afecta y determina la tarea de educar después de que la barbarie haya tenido lugar:

La exigencia de que Auschwitz no se repita es la primera de todas las que hay que plantear a la educación. Tanto precede a cualquier otra, que no creo ni tener que fundamentarla, ni deber de hacerlo. No puedo entender que hasta el día de hoy se le haya prestado tan poca atención. Fundamentarla tendría algo de monstruoso a la vista de la monstruosidad que aconteció. Pero que se tenga tan poca conciencia de dicha exigencia y de las cuestiones que plantea, muestra que lo monstruoso no ha llegado a calar en los seres humanos, síntoma de que la posibilidad de la repetición, por lo que respecta al estado de la conciencia y la inconsciencia de los seres humanos, se sigue manteniendo... Se habla de la amenazante recaída en la barbarie. Pero ella no amenaza, Auschwitz ya fue (Adorno, 1967a, 674).

Si aceptamos con Adorno el carácter epocal de Auschwitz ${ }^{1}$, la exigencia derivada de este acontecimiento de dar cuenta de la dinámica autodestructiva de la racionalidad occidental imbricada con los procesos de modernización científicotécnicos, culturales y políticos y la necesidad de un pensamiento crítico-anamnético que nace de la intención de dar la palabra al sufrimiento, de reclamar los derechos pendientes de las víctimas, de hacer justicia a lo singular frente a toda forma de dominio coactivo, entonces tendremos que aceptar también que la determinación de nuestra situación actual a partir de la catástrofe de Auschwitz posee una significación pedagógica innegable (cf. Peukert, 1991).

La tarea educativa ha estado imbricada con el proceso de reproducción de la sociedad y la cultura en la que Auschwitz fue posible. Educar después de esa catástrofe exige una crítica radical de la propia praxis educativa y de la reflexión teórica sobre la misma. Ya no es posible seguir practicando como evidentes las típicas acciones educativas orientadas por aquella idea de autonomía del sujeto racional y emancipado que le ha venido sirviendo de justificación en el proyecto de la modernidad. Es necesario atender a la imbricación de las instituciones y prácticas pedagógicas con las estructuras sociales que impiden la emancipación. Dichas estructuras someten a los individuos a una enorme presión. Han de doblegarse a sus exigencias de adaptación para poder sobrevivir y los sacrificios que esta adaptación les impone son reciclados por la industria de la cultura y el entretenimiento. Una pedagogía que no reflexione autocríticamente sobre el lugar y la función de

1. Desplegar aquí el sentido de ese carácter epocal desborda el objetivo de este artículo, me remito por ello a otros trabajos en los que he abordado esta cuestión de modo general (Zamora, 2004, 21 y ss.) y en relación con la educación (Zamora, 2008). 
la educación en la reproducción de dichas estructuras, que no perciba cómo la organización social genera y mantiene la heteronomía también a través de las instituciones educativas llamadas a combatirla, no hará sino contribuir a la perpetuación de la barbarie. Por eso creemos que es relevante analizar aquellos elementos de la teoría social, de la crítica de la cultura y de la educación en el pensamiento de Adorno que pueden significar una contribución imprescindible para la elaboración de una teoría crítica de la ecuación hoy.

\section{Dominación SOCIAL E INTEgRaCión SISTÉmica}

Adorno no albergaba ninguna duda respecto a que el punto de partida para desentrañar los fenómenos sociales tiene que ser el de la totalidad antagonista. En este sentido, su teoría de la sociedad es una teoría dialéctica (cf. Meyer, 2005) que denuncia como ideológica toda pretensión de tomar las formas culturales o los hechos sociales concretos como punto de partida absoluto y no como mediados por el proceso de producción y reproducción de la vida social (cf. Adorno, 1969a, 313 y ss.). En un fragmento de Minima moralia, en el que Adorno reflexiona sobre los límites del psicoanálisis, lo viene a expresar de modo contundente: "El sacrificio que exige la sociedad es tan universal, que de hecho sólo se manifiesta en la sociedad como un todo y no en el individuo" (Adorno, 1951a, 66). Cuando queremos reflexionar sobre el papel de la educación, no cabe sino partir del marco social en el que se desarrolla esa tarea, es decir, el de la totalidad antagonista, pues en caso contrario podemos sucumbir a la ilusión de atribuir a la educación el origen de sus contradicciones o sobrecargarla con expectativas emancipadoras que abstraen de su imbricación con el proceso social que marca sus límites y posibilidades ${ }^{2}$.

Este punto de partida no tiene sólo que atender a la prioridad de las estructuras sociales sobre los individuos, sino también a la dinámica que en el caso de la sociedad capitalista impone el mantenimiento del proceso de revalorización del capital. Esto significa, en primer lugar, que la autoconservación de todos y cada uno de los individuos está mediada por el conjunto de la sociedad. La práctica totalidad de los individuos depende de la organización social que les precede y sólo a través de la división del trabajo y los mecanismos que regulan la producción y la distribución de bienes y servicios pueden garantizar su superviviencia. En segundo lugar, si atendemos a la dinámica que impone el proceso de revalorización del capital, lo que

2. Cf. Adorno, 1959a, 93. "No hay que meter el dedo en la llaga de que la formación por sí sola no garantiza una sociedad racional. Ella se agarra desde comienzo a la esperanza engañosa de que puede dar por sí misma a los hombres lo que les niega la realidad... En el ideal de formación que absolutiza a la cultura se manifiesta la cuestionabilidad de la cultura" (ibid., 98). No hay pues posibilidad de una crítica de la formación sin una crítica de la sociedad. Este aspecto ha sido oportunamente subrayado por MAAR, 2003, 468 y ss. 
le confiere a la sociedad un carácter de totalidad (negativa) es que la organización social que a todos abarca y comprende está caracterizada por el antagonismo (dominación y desigualdad). La forma en que la sociedad está organizada, supuestamente orientada a garantizar la autoconservación de sus miembros, genera y reproduce relaciones de dominación de unos individuos sobre otros que no pueden ser atribuidas sin más a la necesaria división del trabajo y a su coordinación.

Esta dominación, a diferencia de las sociedades precapitalistas, en las que es ejercida de manera directa por unos grupos sociales sobre el resto de la población, en el capitalismo tiene lugar de manera mediada e indirecta a través de la abstracción del principio de intercambio y de la ley de reproducción ampliada del capital que reduce a los individuos a agentes y portadores del intercambio de mercancías e impone por esta vía la dominación del universal social sobre lo singular. La finalidad última de la organización social, es decir, garantizar que las necesidades de sus miembros encuentren satisfacción y quede eliminado el sufrimiento evitable (cf. Adorno, 1966a, 203), queda supeditada a la reproducción de unas relaciones de dominación inscritas en el principio de intercambio. La forma de organización social ya no es un medio para alcanzar la finalidad que proclama perseguir, sino que la propia autoconservación se convierte en un medio de la obtención de beneficios (cf. Adorno, 1969b, 361).

Esta inversión es la que, como viera Marx y Adorno con él, se expresa en el concepto de "capital" (cf. Adorno, 1963, 274), sujeto desubjetivado del proceso social dirigido por una especie de mecanismo, la reproducción ampliada del capital, que arrastra consigo a los individuos reducidos a meros productores o consumidores. La inversión que constituye la totalidad antagonista significa sobre todo hipostatización, cosificación autonomizada frente a los individuos. La forma de reproducción del capital es verdaderamente un mundo invertido en el sentido de que, a través de las acciones que aseguran su reproducción y en ellas, se independiza respecto a los individuos que las ejercen, desarrolla una dinámica propia conforme a leyes que funcionan, por así decirlo, a sus espaldas. Esto lo afirman tanto Marx como Adorno no sin ironía, pues su concepto de sociedad pretende ante todo realizar una crítica de esta autonomización de la síntesis social, que es al mismo tiempo construcción ideológica y expresión de la forma específica de desarrollo económico capitalista. Este doble carácter procede del hecho de que los individuos son sujetos y objetos al mismo tiempo. El sistema se constituye gracias a sus acciones, es su resultado, su "naturalidad" es por tanto "pseudonaturalidad" (Naturwüchsigkeit), pero como tal aparece enfrentado a ellos siguiendo una dinámica que les arroya y les convierte en meros ejecutores y apéndices de la objetividad que han producido (cf. Adorno, 1969a, 316).

La objetividad social autonomizada aparece pues como algo externo y contrapuesto, cuya génesis se ha vuelto opaca, casi impenetrable para unos individuos que no son capaces de desentrañar el proceso de autonomización de dicha objetividad, por más que la abstracción real de la suma de valores de cambio no es otra cosa que la cosificación independizada del conjunto de su trabajo. Mientras 
siga vigente la objetividad social autonomizada frente a los individuos, su libertad se verá reducida en gran medida a plegarse a las leyes del mercado, si no quieren ser penalizados con la ruina económica o la marginalidad social. Esto significa reproducir en la propia acción individual la inversión en que consiste el capital, es decir, no perseguir la satisfacción de las necesidades como la finalidad de la acción económica, sino convertir dicha satisfacción en instrumento de una acción económica orientada a la maximización del beneficio.

Adorno utiliza dos conceptos, que no son sin más equivalentes, para nombrar el principio unificador de la totalidad antagonista: el intercambio y la ley del valor (cf. Görg, 2004, 249). Esta última es la forma social específica que adquieren los objetos económicos en el marco de la constitución capitalista de la sociedad. Y en la ley del intercambio Adorno reconoce la misma "objetividad heterónoma" expresada en el concepto de capital, que se presenta a los individuos bajo la forma de coacción (cf. Adorno, 1966a, 171). Así pues, el mundo invertido de la objetividad social autonomizada posee su fundamento en la abstracción operada por el intercambio, que "abstrae de la constitución cualitativa de los productores y consumidores, del modo de producción, incluso de las necesidades, que el mecanismo social satisface como de paso, como algo secundario. Lo primero es el beneficio" (Adorno, 1966b, 13; cf. 1969b, 365 y 1957, 209).

El principio de intercambio nivela y elimina las espontaneidades y las cualidades singulares de los individuos que constituyen la sociedad y los reduce a un denominador común, exige de modo tendencial una equivalencia que actúa de manera abstracta y universal. Según Adorno, esta lógica del intercambio no sólo determina los procesos económicos, sino el conjunto de la vida social; penetra en el conjunto de la realidad social y comporta un dominio de lo universal (sociedad) sobre lo singular (sus miembros), a través del cual termina imponiéndose lo particular en la sociedad antagonista (cf. Adorno, 1969a, 294). Por medio de la introducción de la fuerza de trabajo en el proceso de intercambio se perpetúa el dominio de los que buscan el privilegio y se convierten gracias a la división del trabajo en propietarios de los medios productivos. Así es como dicha dominación adquiere el carácter de una universalidad que oculta su verdadera condición particular. La relación de intercambio posee, según Adorno, un carácter universal, dado que todas las demás formas de relación tienen un rango secundario y están subordinadas al intercambio o asumen funciones compensatorias que refuerzan su superioridad (cf. Adorno, 1951a, 259 y ss.). Pero si bien todo individuo depende para su supervivencia de la participación en la totalidad social que se constituye por medio del intercambio, lo que se realiza a través suyo es el predominio de la totalidad social antagonista sobre las partes (cf. Adorno, 1963, 274). Este carácter tendencialmente totalizador se refleja en la creciente unificación organizativa y tecnológica irracional, unificación tras la que desaparece aquella mediación hasta volverse irreconocible (cf. Adorno, 1969b, 369). El despliegue del principio de intercambio capitalista convierte "el mundo entero en lo idéntico, en totalidad" (Adorno, 1966a, 149). 
Adorno no se refiere a cualquier intercambio, sino a un concepto del mismo cuyo despliegue "conduce en su consecuencia última a la destrucción de la sociedad" (Adorno, 1968, 60). La cuestión, por tanto, es desentrañar la relación que existe entre este tipo de intercambio, la dominación social y la presión a la expansión imparable que acompaña la reproducción ampliada del capital, pues la coacción consiste en que "toda la vida en la sociedad burguesa consolidada se encuentra bajo el principio de intercambio y al mismo tiempo bajo la necesidad -impuesta a los individuos singulares- de apoderarse de cuanto más sea posible, de la mayor cantidad posible del producto social, en la lucha de todos contra todos" (Adorno, 1964/65, 75). Tenemos pues dos elementos cuyo efecto destructor reside en su vinculación: la integración de los individuos en una estructura funcional antagonista y la coacción a la permanente expansión económica.

La distinción entre valor de uso (materialidad cualitativa) y valor de cambio, así como la diferencia entre un plus de producción libremente realizado y un plus de producción coactivamente impuesto bajo relaciones de dominación, explican la razón por la que el valor de cambio (y su multiplicación) se convierte en la finalidad de la producción autonomizada frente a los individuos sociales, un tipo de producción que exige relaciones sociales de dominación para poder tener lugar. La producción se vuelve un fin en sí, en producción para la obtención de beneficio, que no nace sin más del puro intercambio, pero sí del intercambio mediado por el objetivo de multiplicar el valor abstracto, cuya apropiación va unida a estructuras de dominación generadas históricamente. Lo que Adorno afirma en la estela de Marx es que, en el proceso social de reproducción mediado a través del capital total, la producción para la obtención de beneficios lleva a la producción por la producción, a la producción de plusvalía acumulable.

La infinitud de la lógica de la acumulación del capital, de la multiplicación del dinero, no se detiene ante límite natural o humano alguno. Sólo reconoce como meta el incremento de un quantum abstracto. Y para esta abstracción todas las singularidades no son más que obstáculos a superar. Tal y como percibió K. Marx, el capital no posee ningún límite interno, no existe un punto de equilibrio y descanso ${ }^{3}$. Cada vez está más a la vista que si no cambia la racionalidad económica del crecimiento por el crecimiento ese final sólo puede alcanzarse por medio de una catástrofe humana o ecológica. "La relación entre vida y producción que degrada aquélla de modo real a un fenómeno efímero de ésta es consumadamente absurda. Medio y fin son confundidos" (Adorno, 1951a, 13). Y cuando los sujetos son reducidos a medios de la reproducción del capital, no sólo queda arruinada su autonomía, su vida entera pende de dicha reproducción, que es al mismo tiempo la de las relaciones de dominación.

3. "Para el valor coincide multiplicar con conservar y sólo se conserva sobrepasando continuamente su límite cuantitativo, [...]. En cuanto valor [...] es un impulso continuo a ir más allá de su límite cuantitativo; proceso infinito" (MARx, 1974, 936). 


\section{DOMINACIÓN INTERIORIZADA Y DEBILIDAD DE LOS INDIVIDUOS}

Como hemos visto, frente a formas de coacción propias de relaciones de dominación directa, lo específico de la sociedad burguesa es que la coacción está mediada por el sistema económico. La forma propia de dominación capitalista hace que el antagonismo social esté sustraído a la experiencia ordinaria del acontecer social, sólo es accesible a la reflexión. La conciencia de clase cuenta pues con dificultades añadidas, lo cual no quiere decir que su constitución resulte imposible. Sin embargo, Adorno percibe que las formas de dominación social van unidas a mecanismos que impiden a los sometidos la reflexión sobre dicha dominación o, lo que es lo mismo, que es preciso analizar qué es lo que destruye las condiciones subjetivas de una sociedad libre (cf. Claussen, 1995, 29). Una de las diferencias más importantes de la Teoría Crítica respecto a la teoría de Marx quizás sea la consideración de la mediación psíquica de la dominación social como un elemento constitutivo de la teoría de la sociedad. La interiorización de la dominación social incapacita a los individuos para conocer las condiciones sociales de su reproducción individual mediada por el proceso de reproducción del capital. La constatación de Adorno prácticamente al final de su vida es contundente y, en cierto modo, desmoralizante: "Sin que las masas, precisamente a causa de su integración social, dispongan más de su destino que hace 120 años, se desentienden no sólo de la solidaridad de clase, sino de la plena conciencia de que son objetos y no sujetos del proceso social que, a pesar de todo como sujetos, mantienen en marcha" (Adorno, 1969b, 358).

El interés por la autonomía y la posibilidad de afirmación de sí mismo que representa el yo se encuentran en conflicto directo con las exigencias sociales de adaptación, que es el precio para asegurar la autoconservación. Si no quiere ser expulsado del engranaje social, el individuo tiene que acatar las reglas de juego que dicta la situación dominante, pero las exigencias que se derivan de este acatamiento van asociadas a renuncias que no son razonables a primera vista. Ante esto caben dos posibilidades: enfrentarse de modo consciente a la represión social poniendo en peligro la autoconservación o poner en marcha maniobras de suavización y pacificación que impidan tener que soportar grandes mermas de la autoestima o eviten poner en peligro la propia supervivencia. Adorno considera que esta segunda forma es la predominante.

El individuo, realidad derivada, debe su existencia a los mismos poderes que están llevando a cabo diligentemente su disolución. La autodeterminación autárquica, que proclamaba la mayoría de edad del sujeto ilustrado frente a cualquier autoridad, estuvo ya desde el comienzo ligada al intercambio y la propiedad, que ahora en el capitalismo avanzado estrangulan casi toda la capacidad de autodeterminación. A este respecto, es importante destacar que la contradicción es inherente al individuo burgués desde el comienzo (cf. Adorno, 1966a, 259), contradicción entre las exigencias políticas universales y los intereses burgueses particulares, entre la esfera pública y la privada, etc., y, sobre todo, la contradicción 
de que su independencia va acompañada de la opresión de la mujer en el ámbito privado y de la explotación de los asalariados "libres" en el ámbito económico. Por ello el concepto de individuo es, en un sentido genuino, ideología: «El ideal antifeudal de la autonomía del individuo, que se refería a su autodeterminación política, se transformó dentro del entramado económico en aquella ideología, de la que dicho entramado necesitaba para mantener el orden y aumentar el rendimiento" (Institut, 1983, 49). Y el desarrollo económico y político no ha resuelto estas contradicciones, sino que las ha agudizado. Al menos esto es lo que parece confirmar el desmoronamiento de la figura estrictamente liberal del capitalismo, que Adorno percibe en las primeras décadas del siglo XX.

Bajo el manto de la civilización que el capitalismo adquiere en su etapa fordista quedan integradas en la planificación económica y política las condiciones de trabajo y el entorno social como ámbitos organizados. Dicha planificación no tiene necesidad ya de un enmascaramiento ideológico de las contradicciones de clase para estabilizar el sistema. Se dispone a controlar la economía psíquica de los trabajadores. De este modo, la deshumanización sobrevive a través de su aparente superación. El velo encubridor de la tecnología modela al trabajador más a fondo que los procesos de trabajo físicamente demoledores de la primera industrialización, y la cultura de masas "simplemente los vuelve a formar tal como ellos ya son de todos modos bajo la coacción del sistema, controla las brechas, al adversario oficial de la praxis además lo integra en ésta en forma de public moral, les ofrece modelos para la imitación" (Adorno, 1942, 390 y ss.). Puesto que la deshumanización hiriente pone en peligro al sistema, éste se sirve de la civilización como instrumento de dominación y somete a los miembros de la sociedad recreándolos a su imagen y semejanza. La deshumanización se vuelve inmanente al sistema, que ya no necesita excluir a nadie de la 'cultura' porque ésta se ha convertido en el instrumento con el que todos quedan incluidos. La ideología, en el sentido de una mediación entre autonomía y dominación, ya no es necesaria, porque ya no hay nada que temer de la autonomía.

Esto no significa que la interiorización de la dominación social, que se manifiesta en la identificación con el colectivo social, sea vivida por los individuos sin conflictos psíquicos. El análisis de los mecanismos y esquemas que intervienen a la hora de afrontar esos conflictos y los efectos que tienen sobre el conocimiento y la voluntad de los individuos bajo las actuales condiciones de socialización constituyen, según Adorno, el objeto de una sociología abierta a las aportaciones del psicoanálisis (cf. Adorno, 1959b, 147) . Fundamentalmente estos mecanismos y esquemas adquieren forma en el "carácter autoritario" y el "narcisismo herido".

4. Evidentemente esto supone la posibilidad de conflictos estructuralmente idénticos en individuos diferentes. Para que sea plausible esta identidad estructural es necesario referirse a la constitución preindividual e indiferenciada del inconsciente y, al mismo tiempo, presuponer la existencia de conflictos típicos entre las agencias socializadoras y los individuos en su fase de evolución temprana. 
Ambos suponen una interiorización de la dominación y un deterioro de la capacidad de reflexión objetiva sobre las propias condiciones sociales de vida 5 .

Las condiciones sociales e históricas alteran el acceso del yo a la satisfacción de los impulsos, a una sublimación no represiva, a una fortaleza del yo sin acorazamiento debido al principio de la autoconservación y a una socialización solidaria sin represión adicional. En este sentido es en el que la situación de los individuos en el capitalismo tardío, situación responsable de un especial debilitamiento de los seres humanos y de su subjetividad, produce nuevas formas agudizadas de empobrecimiento y regresión psicosociales. Aquellas condiciones que confieren al individuo fuerza frente a la sociedad han sido prácticamente eliminadas. Las formas mediadas de subjetividad, de capacidad de experiencia y disfrute, la relevancia de la sublimación y la necesidad de ella, etc., son sustituidas cada vez más por la intervención directa de la sociedad en la economía pulsional de los seres humanos. El sujeto del siglo XX pierde su autonomía, su fuerza moral y espiritual, la experiencia marcadamente placentera y su capacidad de resistencia frente a la presión social para la adaptación.

Cuando el yo es demasiado débil para desarrollar la capacidad de integrar los deseos pulsionales a veces avasalladores, las rígidas pretensiones del super-yo y las exigencias de la realidad, los conflictos internos no pueden ser resueltos y llevan a reacciones angustiosas y oprimentes. Los individuos se convierten en el curso de la fracasada ontogénesis de su proceso de socialización en "cautivos de su propio yo debilitado" (Adorno y Horkheimer, 1952, 369). La adaptación al poder o las convenciones y la identificación con la dureza, el dinero, el rendimiento o el poder, que en realidad son imposiciones de la sociedad, se convierten en determinantes del yo debilitado, que proyecta su odio hacia todos los que real o supuestamente se sustraen a esas imposiciones. Incapacitado para establecer un sistema autónomo de valores morales consistente y duradero, se ve obligado a acogerse a poderes sociales más poderosos, de los que hace depender sus decisiones morales.

5. No puedo entrar aquí extensamente en el análisis de ambas formas de carácter, cf. ZamORA, 2007, 27-42. Su clave está en el conflicto entre la necesidad de una ocupación libidinal de la propia persona y el agravio permanente que las condiciones sociales infligen a los individuos para asegurar la autoconservación. Dichas condiciones son percibidas como ajenas, extrañas o destinales y, al mismo tiempo, como precarias, cuando no asociadas a insuficiencias de los propios sujetos amenazados, pero raramente identificadas como resultado de coacciones sistémicas. Si las exigencias de autoconservación reclaman una ocupación libidinal adicional de la propia persona (narcisismo), la incapacidad de controlar las condiciones de existencia provoca un agravio permanente que abre y reabre la herida narcisista. La solución a este conflicto se produce a través de la colectivización del yo gracias a la identificación compartida. El narcisismo dañado encuentra cumplimiento en el narcisismo colectivo. "La debilidad del yo hoy, que no es simplemente psicológica, sino en la que el mecanismo psíquico registra la impotencia real del individuo frente al aparato socializador, estaría expuesta a una dosis insoportable de agravio narcisista, si no se buscara una compensación a través de la identificación con el poder y la grandeza del colectivo" (Adorno, 1961, 580). 


\section{De la cultura burguesa a la industria cultural}

Un factor fundamental de integración de los individuos debilitados y fragilizados en el capitalismo tardío es la industria cultural ${ }^{6}$, generada por el mismo proceso de totalización capitalista de la sociedad ${ }^{7}$. A través de ella, el aparato productivo interviene en la configuración de las necesidades, estructura la conciencia y coloniza la fantasía, haciendo extremadamente difícil un pensamiento autónomo y una praxis de transformación radical. Lo que hace la industria cultural es reforzar la integración de los individuos contribuyendo a que reconozcan y acepten su insignificante valor y su intercambiabilidad, es decir, que se reconcilien con el hecho de haberse vuelto prescindibles como individuos singulares y autónomos en el capitalismo avanzado. Lo que le sucede a la cultura bajo el imperativo del principio de intercambio capitalista, la denigración de su valor de uso a medio de entretenimiento y distracción, tiene por tanto un carácter ejemplar para el conjunto de la sociedad: su tendencia al conformismo, a la trivialización y a la estandarización se corresponde con el proceso histórico de "desaparición del individuo" en cuanto signatura de toda una época.

Los seres humanos adoptan una actitud afirmativa respecto a la cultura de masas, porque saben o presienten que en ella les son enseñadas las mores de las que tienen necesidad como salvoconducto en la vida monopolizada. Dicho salvoconducto sólo tiene validez cuanto está pagado con sangre, con la cesión de toda la vida, con la obediencia apasionada frente a la odiada coacción. Por esa razón y no por la "idiotización" de las masas, que llevan a cabo sus enemigos y denuncian sus amigos, resulta la cultura de masas tan irresistible (Adorno, 1980, 331).

A pesar de que Adorno no albergara ninguna ilusión respecto a la elevada cultura burguesa, que siempre dependió del privilegio social y educativo, se le ha acusado repetidamente de elitismo cultural por su crítica de la cultura de masas. Pero la industria cultural no es simplemente lo contrario de la cultura elevada, no supone una degeneración de lo sublime y excelso del arte burgués a causa de su masificación. Al contrario, dicho concepto analiza las últimas consecuencias de una autonomización de la cultura que tiene lugar gracias al mercado capitalista, del que es deudora y que, como en el caso del individuo, termina produciendo un total sometimiento a sus leyes y conduciendo a la aniquilación de toda autonomía.

6. El potencial del efecto de la industria cultural «es promover y explotar la debilidad del yo, a la que de todos modos la sociedad actual, con su acumulación de poder, condena a sus miembros impotentes" (Adorno, 1967b, 344).

7. Cf. Adorno, 1966b, 17. Sobre el concepto de "industria cultural" existe una extensa bibliografía. Remito al excelente y exhaustivo trabajo de Duarte, 2003a. Ver también los estudios de STEINERT, 1998 y 2007.

8. Sobre la relación entre cultura popular y cultura de elite y entre ambas y la industria cultural, cf. el lúcido artículo de ZuckermanN, 2000. 
La constitución antagonista de la sociedad afecta a toda manifestación cultural, convirtiéndola al mismo tiempo, como decía W. Benjamin, en expresión de la barbarie (Benjamin, 1940, 696). Se trata del estigma que la acompaña desde siempre. El trabajo en cuanto trabajo asalariado debe estar disponible a discreción de la economía y la pretensión de autonomía y autorrealización de los sujetos se ve desplazada a la esfera separada del "espíritu". Autorrealización y autoconocimiento tienen pues una esfera propia, han de realizarse en el ámbito de lo cultural sin interferir negativamente en otros ámbitos. Pero precisamente esa separación somete a la cultura a las leyes de la sociedad antagonista y a su dialéctica.

Adorno ve, sin embargo, en este distanciamiento respecto al proceso de reproducción económica en su inmediatez, es decir, en cuanto resultado del despliegue de las fuerzas técnicas de producción, la idea de una configuración humana de la vida más allá de las coacciones económicas. Se podría hablar de un potencial utópico y crítico inherente a la cultura, que, sin embargo, no puede ser realizado cuando ésta niega su imbricación con las estructuras de dominación social, es decir, cuando reifica su separación como cualidad esencial del espíritu y no se reconoce como hecho social, sirviendo entonces de sublimación, compensación, legitimación o simplemente evasión de dichas estructuras. "El doble carácter de la cultura, cuyo balance como quien dice sólo se consiguió de manera esporádica, surge del antagonismo social irreconciliado, que la cultura pretende curar y que en cuanto mera cultura no puede curar" (Adorno, 1959a, 96).

En el capitalismo avanzado, con el establecimiento de la industria cultural, se transforma el contenido de la cultura. Y esto significa la pérdida del grado de autonomía (relativa) de que gozaba en la época liberal-burguesa. En la nueva etapa del capitalismo acechan por todos lados las instancias integradoras y al individuo no se le concede ni el privilegio de la cultura burguesa ni la experiencia de estar excluido de ella. Asistencia y control, diversión y entontecimiento, se funden en una ideología poderosa, que no sólo tiene su base en la realidad social, sino que coincide tendencialmente con ella. Los ritmos musicales y los anuncios que martillean permanentemente a los individuos desde los medios de masas les arrancan literalmente de la cabeza el pensamiento crítico. Y las imágenes que la televisión emite igualmente sin pausa tejen el velo encubridor más tupido. El conformismo es entrenado y exigido. "Existir en el capitalismo tardío es un permanente rito de iniciación. Cada uno tiene que mostrar que se identifica sin reservas con el poder que le golpea" (Adorno y Horkheimer, 1947, 176).

En la difusión de la industria cultural (cine, radio, prensa, música, televisión, etc.), en la que el principio de intercambio de la sociedad productora de mercancías se adueña por completo del ámbito de la cultura, Horkheimer y Adorno perciben la caricatura grotesca del programa ilustrado de una cultura universal para la humanidad. La relativa distancia frente a ese principio, presente todavía en las obras de arte autónomo burgués, que en su inutilidad denuncian el reino de la fungibilidad absoluta, es tendencialmente eliminada por la industria de la cultura: sus productos no son también mercancías, sino que lo son absolutamente. La 
producción cultural bajo los imperativos del mercado penetra hasta el núcleo formal de la construcción de sus productos. En esta industria la cultura se convierte en un asunto de los grandes grupos empresariales y de la administración, que se apoderan de ella para estandarizarla y homogeneizarla de acuerdo, por un lado, con la finalidad del beneficio económico y, por otro, con el interés en la estabilización de una situación social hostil a la autonomía de los individuos?

Sin embargo no conviene olvidar que la neutralización del potencial crítico de la cultura, que ha limado su aguijón contra el statu quo, estaba ya inscrita en la tendencia afirmativa de la propia cultura en su etapa liberal-burguesa, tendencia a hipostatizarse como un reino puro y separado de la praxis social abandonada a sí misma; precisamente "al perder el concepto de cultura su posible relación con la praxis, se convierte él mismo en un elemento de la mecánica de funcionamiento; lo retadoramente inútil se convierte en lo fútil tolerado o incluso en lo perversamente útil, en lubricante, en algo que es en función de otra cosa, en falsedad, en mercancías de la industria cultural calculadas para los clientes" (Adorno, 1960, 132).

En la industria cultural se da cumplimiento a las exigencias que provienen de la reestructuración del capitalismo en la fase que ha dado en denominarse fordista, que combina la racionalización de los procesos productivos, el disciplinamiento de la fuerza de trabajo, la producción masiva de bienes de consumo estandarizados y la elevación de la capacidad adquisitiva de la clase trabajadora, al menos en los países más desarrollados. Todas las mercancías necesitan crear la ilusión de un valor emocional, vivencial, cultural, etc., más allá, independientemente o incluso contra su utilidad, para lo que toman a su servicio la industria cultural. Pero también el ámbito cultural, vivencial, emocional, etc., es susceptible de comercialización. La cultura es producida de la misma forma y bajo las mismas condiciones que el resto de productos. Se producen de modo masivo las mismas categorías de mercancías por procedimientos especializados, es decir, de modo técnicamente eficiente, según cálculos de rentabilidad y beneficio. Estos procedimientos apuntan a la estandarización y la uniformización de sus productos, a la producción en serie y la distribución en masa. Los criterios que rigen la producción y distribución de "bienes culturales" no se distinguen para nada de los del resto de mercancías que pueblan el mercado. La diferenciación y diversificación de los productos está al servicio del abastecimiento general conforme a las reglas de estudio de mercado.

Para garantizar la rentabilidad y el beneficio la industria cultural promueve una fusión de cultura y entretenimiento. En la diversión ofrecida por la industria

9. Aunque la crítica de la industria cultural en la Dialéctica de la Ilustración no exhibe la misma capacidad diferenciadora que el análisis de las obras de arte moderno llevada a cabo por Adorno, dicha crítica no pretende condenar los productos inferiores de la cultura de masas desde la atalaya de la estética normativa elitista de la burguesía culta, como tantos pretenden (cf. p. ej. Kellner, 1983, 482 y Ss.; Seel, 1987, 11 y ss. Contra esto cf. Claussen, 1990, 134-150). 
de la cultura se tiende a borrar todo atisbo de nuevas exigencias o pretensiones inesperadas dirigidas a un pensamiento independiente y a una acción de los individuos en cuanto sujetos autónomos. Aquellas capacidades que no pueden ser desarrolladas durante el tiempo de trabajo, tampoco en el tiempo libre encuentran posibilidades de despliegue. Pretextando suministrar placer y diversión a las masas, evasión de lo cotidiano, en realidad la risa decretada por la industria cultural se convierte muy frecuentemente en un instrumento para estafar la felicidad" (Adorno y Horkheimer, 1947, 162).

La cultura producida como mercancía, es decir, buscando la facilidad de venta y por ello bajo la promesa de una satisfacción rápida y sencilla, está al servicio del engaño del comprador, pues le promete una experiencia que, sin embargo, resulta inalcanzable como pura diversión y estridente entretenimiento. Esa forma de congraciarse paternalistamente con la supuesta (in-)capacidad de comprensión del público elimina de los productos culturales lo que éstos tienen de desafío y provocación y desprecia a sus destinatarios precisamente en el gesto de atención que expresa la frase "su deseo es una orden". La industria cultural promueve la identificación con sus productos y por este medio con la realidad dada. Con su "jerga de la comunicación sin límites" (Adorno, 1980, 307) abarca todos los ámbitos de la sociedad, ejerce un control casi total en el sentido de asegurar la conformidad. Aunque ésta, a su vez, es el resultado de la predisposición a adaptarse producida por una red omniabarcante de instituciones de la industria cultural. Su función principal es generar esa conformidad de principio con la disposición actual del mundo, procurar una conciencia fundamentalmente afirmativa a pesar de las discrepancias en detalle: "La industria de la cultura es integración desde arriba expresamente querida por sus clientes" (Adorno, 1967b, 337).

A pesar de que la producción cultural está dominada por el principio de estandarización, el ardid comercial consiste en presentar los productos de la industria cultural como lo contrario, como algo modelado artísticamente de manera individual y completamente único. Los rituales de la cultura de masas simulan la individualidad que ellos mismos ayudan a sofocar. La espontaneidad que haría posible la constitución de la individualidad es eliminada al mismo tiempo que se simula su existencia (cf. König, 2000, 19). Cuanto "más deshumanizado" es el sistema de funcionamiento de la industria cultural, "tanto más diligente y exitosamente propaga las presuntas grandes personalidades y opera con tintes sentimentales" (Adorno, 1967b, 340). Aunque la industria de la cultura escenifica lo individualmente llamativo de la personalidad como aquello que constituye su atractivo, sin embargo, es lo suficientemente cínica como para revelar lo que el brillo exterior tiene de fachada.

No es necesario buscar trabajosamente la prueba del carácter comercial de los productos culturales, la ofrece la misma industria cultural convirtiéndola en propaganda: la mejor publicidad es el número de ventas. De este modo se quiebra la oposición entre verdad e ideología. Esta última es el anuncio arrogante y cínico de que sus productos no son más que negocio, cuando con ello se reprimen las 
posibilidades de algo diferente. Esta nueva figura de ideología no pretende, pues, engañar sobre la realidad, le basta con reprimir las posibilidades de su transformación presentando la realidad establecida en su prepotencia como inevitable. Precisamente porque en la industria de la cultura tienden a desaparecer las ideologías manifiestas y tan sólo se hace "publicidad para el mundo por medio de su reduplicación" (Adorno, 1951b, 29), produce dicha industria un acuerdo general con el orden dominante en cada momento. El enmascaramiento resulta de la falsa inmediatez producida por el medio, pese a su carácter de construcción selectiva y composición formal.

\section{De la formación (BILDUnG) a la pSEudoformación (HalbBiLdunG)}

Los términos "Bildung" y "Halbbildung" remiten a la apropiación subjetiva de la cultura en el período liberal burgués y en la época de la industria cultural respectivamente (cf. Adorno, 1959a, 94). Estos términos no tienen una fácil traducción a las lenguas románicas. Podrían traducirse por educación o formación entendidas de modo general como el modo institucionalizado de apropiación de la cultura por parte de los individuos que da forma a su individualidad. En el lenguaje ordinario, sin embargo, educación o formación han quedado reducidas a un medio práctico de realizar de manera ventajosa la carrera profesional. Esta reducción es sintomática del proceso que produce el vuelco de formación en pseudoformación, un proceso que corre de manera paralela al que protagoniza el vuelco de la cultura moderna en industria cultural. La dialéctica de la cultura en la sociedad capitalista tiene pues una correspondencia en el plano de su apropiación subjetiva: «La industria cultural tiene como modelo la pseudoformación" (Behrens, 2004, 144).

La formación de los sujetos en el sentido que inaugura el giro subjetivo de la modernidad estaba vinculada a la afirmación de la autonomía y la libertad de los individuos y ésta a su vez a la formación de una sociedad que, por medio de la revolución de las relaciones sociales, económicas y políticas, hiciese posible la realización de la autodeterminación de los sujetos emancipados. La idea filosófica de formación (Bildung) en su momento de esplendor pretendía "formar la existencia natural conservándola” (Adorno, 1959a, 95), es decir, perseguía una relación humanizadora entre sociedad y naturaleza. Esta relación se ve frustrada por una dominación de la naturaleza desbocada que niega la libertad y la soberanía que pretende alcanzar frente a ella y da un vuelco en un nuevo sometimiento al orden social naturalizado y enfrentado a los individuos que lo producen.

Existe un vínculo entre la dominación desbocada de la naturaleza, la dominación social y la dominación en el sujeto mismo. Una relación social con la naturaleza capaz de generar humanidad, que no la reduzca a mero substrato de explotación económica, exige una sociedad no fundada en el antagonismo social que convierte el aprovechamiento económico en principio prevalente de organización de la sociedad, produciendo y reproduciendo la dominación social y 
frustrando la formación de individuos libres y autónomos, cuya supervivencia bajo estas condiciones exige la adaptación al todo social antagónico y la mutilación de su propia dimensión natural. La idea de Bildung era en su origen un campo de fuerzas entre espíritu y naturaleza, individualidad y cultura, subjetividad y sociedad, sensitividad y comunicación, etc., en el que intervienen las relaciones sociales, las relaciones con la naturaleza y las relaciones de los individuos con su propia dimensión natural. El logro de la formación de los sujetos dependía de la formación de una totalidad social libre de dominación y de una relación entre cultura y naturaleza que formase la existencia natural conservándola.

Adorno asocia la frustración del proyecto emancipador revolucionario con la petrificación y la escisión del campo de fuerzas constitutivo de la formación (Bildung). Su concepto se desentiende de la transformación de la totalidad social según criterios racionales y coloca en su lugar al individuo singular convertido en supuesto fin en sí mismo. Al mismo tiempo la totalidad social se organiza según el principio de la competitividad y del interés "racional" por el propio beneficio, abandonando al mecanismo "invisible" del mercado la consecución de la unidad entre lo singular y lo universal o esperando del dominio científico-técnico de la naturaleza el progreso de la humanidad. El resultado es una escisión entre una cultura del espíritu y una dominación adaptativa de la naturaleza, entre un ideal de educación (Bildung) más allá de todo orden instrumental y una formación (Ausbildung) volcada en la adaptación a una dinámica ciega de totalización social y a una praxis de dominación capitalista del mundo y de sí mismo (cf. Adorno 1959a, 97 y ss. $)^{10}$, una escisión que simplemente refleja de manera acrítica la tan manida contraposición entre humanismo y técnica (cf. Adorno, 1962): "La misma escisión entre técnica y humanismo", afirma Adorno contra los que le tachan de elitismo cultural burgués, "por muy insalvable que se crea, es parte de una apariencia socialmente producida" (Adorno, 1953, 314).

El destino de la formación burguesa (Bildung) en la sociedad capitalista es inseparable de esta escisión y de la eliminación de la tensión que todavía resulta reconocible en parte en los comienzos de la literatura burguesa, especialmente en la "novela de formación" "11. La funcionalización de la educación como formación

10. Cf. Blankertz, 1985. La enseñanza se divide pero mantiene el mito educativo de la personalidad desarrollada en plenitud bajo el supuesto de que existe un camino según la presunta capacidad de cada uno para alcanzarlo, ya sea a través de la carrera profesional o a través de la ocupación no utilitaria con la verdad, el bien y la belleza. Esto permitió ofrecer una educación del espíritu universal como formación profesional de los dominadores y una formación profesional como educación universal de los dominados.

11. En la poesía dramática de Schiller todavía reconoce Adorno la escenificación de la tensión entre las pasiones naturales del individuo y el orden político del poder. Sus Cartas sobre la educación estética del hombre tematizan esa problemática en una concepción de la educación que cultiva, civiliza y moraliza la tensión entre la pretensión idealista de la juventud y las sobrias exigencias burguesas de una vida profesional, entre las condiciones de una autonomía económica y la búsqueda de libertad 
profesional del empresario/comerciante o el técnico/científico va de la mano de la entronización de los productos de la cultura del espíritu como representantes únicos de la cultura en su conjunto, que los individuos consumen como «bienes culturales" puros, pero cosificados y convertidos en privilegio de clase y signo de la posición social. Esto explica que, para Adorno, la pseudoformación no sea sin más lo opuesto a la formación, sino la culminación de un proceso incoado en la misma constitución de la formación burguesa como apropiación de una cultura del espíritu segregada de la producción y reproducción material de la vida social (cf. Behrens, 2004, 137 y ss.). "La cosificación de la conciencia, la disposición sobre su afilado aparataje se interpone frente a los objetos e impide la formación (Bildung) que coincidiría con la resistencia frente a la cosificación" (Adorno, 1962, 497).

Aquello que se sustrae a la formación profesional (Ausbildung), aquello de lo que hay que abstraer para participar en el intercambio social como productor o consumidor, que no es exigido ni recompensado por el mercado de trabajo, queda señalado con la marca de lo inútil, su destino queda vinculado al "tiempo libre" o es desplazado a la marginalidad de lo genial y lo excéntrico. La cultura del espíritu es confinada a los círculos del arte, donde es celebrada vanidosamente como autonomía frente a la praxis social alienada bajo los imperativos del sistema productivo y como ámbito de una individualidad ampliada o una interioridad no funcionalizada. Pero esto supone en realidad su neutralización y posibilita otra forma de funcionalización. "Lo que parece decadencia en la cultura es su pura consumación" (Adorno, 1951b, 17).

A pesar de que parece ser aquello que se sustrae al poder del intercambio, aquello que tiene un valor en sí, que permite una inmediatez de relación más allá de la mediación mercantil, la cultura del espíritu como esfera segregada y conjunto de bienes producidos para el mercado cultural quedará casi completamente subsumida por sus leyes. Esto ocurre en lo que Adorno identifica como consumo del valor de cambio:

Si la mercancía se compone de valor de cambio y valor de uso, el puro valor de uso, cuya ilusión han de mantener en la sociedad totalmente capitalista los bienes culturales, es sustituido por el puro valor de cambio, que precisamente asume engañosamente, en cuanto tal valor de cambio, la función del valor de uso. En ese quid pro quo se constituye el carácter específicamente fetichista de la música: los afectos, que se proyectan sobre el valor de cambio, crean la apariencia ilusoria de lo inmediato, y la carencia de relación con el objeto la desmiente al mismo tiempo.

\footnotetext{
y moralidad en el sentido de una formación del individuo en el ámbito del espíritu. "Una vez que desaparece esa tensión, se vuelve hegemónica la adaptación, su medida es lo dado en cada caso. Prohíbe elevarse sobre lo dado, sobre lo positivo, desde la determinación individual. A causa de la presión que ejerce sobre los hombres, perpetúa en ellos lo deforme que pretende haber formado, la agresión" (AdORno, 1959a, 95).
} 
Dicha inmediatez se basa en el carácter abstracto del valor de cambio (Adorno, 1938, 25).

Aquí la ilusión es perfecta: la mediación total se presenta como absoluta inmediatez, se hace prácticamente irreconocible. Se produce una sustitución del valor de uso por el valor de cambio que termina afectando a la estructura misma de los "bienes culturales" producidos para el mercado y a la relación con ellos. Los consumidores de cultura adoran esos bienes como objetos cosificados, que separados de su origen pasan por objetos sublimes e impenetrables, en vez de como personificaciones de las relaciones sociales. La cultura se consume como si se tratara de un bien del que se dispone para estar informado o mostrarse cultivado. El "disfrute secundario del prestigio, del "estar presente" (Adorno, 1970, 32 y ss.) es lo decisivo y no una confrontación viva con los contenidos culturales.

La pseudoformación refleja una situación social en la que, al menos tendencialmente, todos son "abastecidos a través de innumerables canales con bienes formativos", pero al mismo tiempo, por un lado, "los contenidos de la formación, a través del mecanismo del mercado, son adaptados a la conciencia de aquellos que fueron excluidos del privilegio de la formación y para cuya transformación debería existir la formación" (Adorno, 1959a, 100) y, por otro lado, la presión ejercida por la socialización capitalista tiende a negar a todos, no sólo al proletariado, las condiciones económicas y psíquicas de dicha formación. La "estructura social y su dinámica impiden que los bienes culturales, tal como corresponde a su propio concepto, sean apropiados de manera viva por los neófitos" (Adorno, 1959a, 100). Ya no se trata de una separación entre el privilegio de la formación y la exclusión de la misma por la división de clases. La producción y distribución masiva de bienes culturales por la industria de la cultura, así como su apropiación subjetiva bajo las nuevas condiciones que los vacían y reducen a meras mercancías produce una igualación en la manera de apropiación por parte de todos los individuos, por más que las diferencias sociales estén lejos de haber desaparecido. Pseudoformación no es la falta de formación de las clases subalternas, sino la forma dominante de la conciencia actual.

En la pseudoformación la apropiación del "capital cultural" (Bourdieu, 1988) sirve para estar informado, para tener un determinado grado de formación, unos títulos, etc., es decir, una posesión que permite tener ventajas en la lucha competitiva, alcanzar determinadas posiciones sociales, lograr un nivel económico adecuado, etc. Para Adorno resulta sospechoso todo intento de concreción pragmática de la emancipación, es decir, todo intento de limitarla en razón de las exigencias que establece la sociedad, las supuestas necesidades de los educandos o, incluso, la coacción que impone la simplificación metodológica de transmisión de contenidos educativos. Y la razón de esta sospecha es bien clara: la pseudoformación socializada no ofrece ninguna resistencia frente a la barbarie, como pone de manifiesto la paradoja que tanto sorprende a los que conocen la realidad de los campos de exterminio nazis: la coincidencia del disfrute de los bienes culturales del espíritu 
y la disposición para la aniquilación masiva de seres humanos. Tan pronto como la cultura del espíritu queda identificada con los "bienes culturales" o con los "contenidos educativos", tan pronto como sus "productos" se convierten en algo sobre lo que hay que estar informado para poder intervenir, en algo que se debe conocer para aparecer como un individuo cultivado, preparado, a la altura, etc., pierden su verdadero carácter emancipador.

La pseudoformación no permite que los sujetos entren en una relación viva con las producciones culturales y los contenidos educativos para apropiarse su contenido de verdad. Éstos tampoco ofrecen ya la resistencia que sería necesaria para que exista una confrontación intensa sin la que es imposible entregarse al objeto de la experiencia. El mundo que el individuo hambriento de experiencia quiere apropiarse desaparece sin brillo para dejar sitio a un mundo preparado y adaptado a sus deseos de consumo. En realidad no es posible "experimentar" un mundo preparado para el consumo, sólo se puede comprar y consumir. Una vez canjeada la competencia para dar forma a la propia vida por un dejarse abastecer con fragmentos de mundo preparados para consumir, los individuos se vuelven demandantes menesterosos de individualidad, pero ésta, una vez perdida aquella competencia, ya sólo depende de la capacidad adquisitiva, de la fuerza para imponerse a la competencia y del refinamiento del gusto. La singularidad se diversifica según la clase de mercancías que pueden adquirirse.

La experiencia es "sustituida por un estar informado de manera puntual, inconexa, intercambiable y efímera, al que se le nota que en el próximo instante será borrado por otras informaciones" (Adorno, 1959a, 115). Simulando ser un reflejo de la realidad, la información tiende a convertirse en su sustituto, eliminando la capacidad de penetración dialéctica que moviliza las posibilidades no cumplidas contra lo simplemente dado y de trascenderlo mediante el desvelamiento de sus contradicciones. De ese modo triunfa la adaptación a lo existente. De ello son reflejo los clichés a que quedan reducidos los conceptos de los que se ha eliminado la corrección dialéctica y la posibilidad de una relación no cosificada entre sujeto y objeto ${ }^{12}$. El "espíritu de la pseudoformación está juramentado con el conformismo" (Adorno, 1959a, 115), de él desaparecen todos los elementos de la crítica y de la distancia frente a lo dado que una vez fueron constitutivos de la formación. En vez de apuntar más allá de la mala realidad por medio de la experiencia reflexiva, la pseudoformación abastece a los sujetos con esquemas para dominarla y lleva a cabo así un "cortocircuito permanente" (Adorno, 1959a, 117).

12. R. Duarte ha mostrado que la teoría de la pseudoformación permite enlazar elementos de la crítica de la industria cultural y del antisemitismo referidos a la usurpación del esquematismo por la primera y a la falsa proyección en el segundo, ambos relacionados con la destrucción de la experiencia de la que aquí hablamos; ver Duarte, 2003b, 441-457. 


\section{De LA PSEUdOFORMACIÓN A LA "SOCIEDAD DEL CONOCIMIENTO"}

La clave fundamental que permite desentrañar el proceso dialéctico que produce un vuelco de la cultura en industria cultural y paralelamente de la formación en semiformación es la que recoge la fórmula adorniana de "cultura como mercancía". Como hemos visto, en el concepto de pseudoformación Adorno analiza el destino de la apropiación subjetiva de los contenidos establecidos por el canon clásico de la cultura burguesa sometidos al régimen de la industria cultural y distribuidos masivamente por los incontables canales de los que dispone dicha industria. Muchos de sus ejemplos se refieren al tratamiento de la música clásica en los programas de entretenimiento. Sin embargo, Adorno no presta la misma atención a la dimensión de la educación que en su teoría de la pseudoformación resulta de la escisión entre una cultura del espíritu y una dominación adaptativa de la naturaleza, entre Bildung y Ausbildung; esta última volcada directamente en la adaptación a una praxis de dominación económica capitalista del mundo y de sí mismo.

Aunque el ideal educativo, a través de la especialización de las ciencias del espíritu y las ciencias de la naturaleza, ha mantenido largo tiempo la exigencia de transmitir tanto la cultura del espíritu como los saberes científico-técnicos que entran directamente a formar parte de la infraestructura del sistema productivo capitalista, la progresiva división del trabajo y la creciente hegemonía del aparato tecnológico y la organización económica han transformado el ideal educativo tradicional. Aparentemente su meta ya no es el individuo con talentos diversos y formado de manera integral, sino el productor disponible en el mercado y juramentado con los objetivos de la economía. La pedagogía se vuelca en la optimización de los procesos de aprendizaje en relación con su relevancia para el trabajo económicamente rentabilizable. Formar es sobre todo ofrecer una cualificación para el mercado de trabajo.

Esta transformación de la educación en formación profesional, del saber en conocimientos rentabilizables económicamente, se remonta a la época del imperialismo y caracteriza todo el siglo XX. El capitalismo intervencionista favoreció el empleo masivo de las ciencias naturales y de los saberes tecnológicos en la racionalización de los procesos productivos y de las ciencias jurídicas y sociales en la racionalización de la burocracia económica y estatal. El crecimiento exponencial de los conocimientos científicos, tecnológicos, jurídicos, administrativos, etc., fue arrinconando y reduciendo los contenidos del ideal clásico burgués de cultura, que ha terminado por perder significación para aquella apropiación cosificada que Adorno identifica con el concepto de pseudoformación. Incluso ese concepto de formación entendido como proceso de apropiación de «bienes culturales" parece haberse vuelto complicado y poco práctico para la lógica de aprovechamiento según los intereses del beneficio. Si la crítica de la pseudoformación todavía podía remitirse a un concepto de formación contradictorio y periclitado, pues para aquélla seguía siendo la formación clásica el concepto ideológico de referencia, ahora éste parece haber perdido toda utilidad y legitimidad (cf. Liessmann, 2006). 
Esta tendencia se percibe con más intensidad a partir de la crisis económica mundial de los pasados años setenta que supuso una pérdida del equilibrio posbélico entre productividad, necesidad de fuerza de trabajo y consumo y que abrió las puertas de la era neoliberal. La estrategia neoliberal promueve una completa disolución de la teoría de la sociedad en saberes parciales especializados acorde con su idea de que el gobierno estatal de la economía y la sociedad debe ser sustituido por la competitividad desregulada del mercado. Ésta se convierte en el principio al que deben someterse todos los ámbitos políticos imaginables, también la cultura y la educación, desde las escuelas primarias a las universidades. Se proclama la necesidad de reformar las instituciones educativas para convertirlas en "empresas del conocimiento" dentro de un mercado supuestamente abierto, orientadas sobre todo a producir recursos humanos rentabilizables económicamente. El vínculo, que siempre fue ideológico, entre formación, emancipación política y humanidad es declarado definitivamente como obsoleto por la nueva ideología (cf. Stapelfeldt, 2007, 59 y ss.). El "conocimiento" y los servicios vinculados a él (enseñanza, consultoría, entretenimiento) son identificados como los medios de producción más importantes en una sociedad definida por el discurso dominante como "sociedad del conocimiento".

La exigencia de nuevos impulsos de productividad y tecnificación producida por la presión de la competitividad a escala mundial tiene efectos destructivos sobre la necesidad de fuerza de trabajo. Al mismo tiempo, la internacionalización del capital promovida por los mismos Estados reduce la intervención de éstos a facilitar la ejecución, en el mejor de los casos políticamente atemperada, de la ley capitalista del valor que actúa casi sin cortapisas en el mercado mundial (cf. Hirsch y Roth, 1986, 65). También el sistema educativo es sometido a esta misma presión. La formación es presentada como un factor fundamental en la lucha competitiva que impone dicho mercado para asegurar un empleo con mayor productividad y vinculado a los sectores de la producción con un mayor valor añadido. El "capital humano" se convierte en el factor productivo de mayor importancia para un futuro incierto y los individuos se ven confrontados con la exigencia de una (re)cualificación permanente ante la amenaza, en caso contrario, de hundimiento y fracaso total en la lucha competitiva universal. La formación reducida a cualificación profesional se orienta unidimensionalmente a la promoción de aquellas capacidades y talentos que prometen una utilidad económica actual. Y las instituciones educativas son evaluadas por el mismo criterio, es decir, según sirvan o no al proceso productivo, a aumentar la competitividad de la economía o a mejorar las oportunidades de ingreso y ascenso de quienes pasan por ellas.

El llamado proceso de Bolonia, la creación de un Espacio Europeo de Educación Superior (EEES) (Sanz, 2005), si levanta tantas sospechas es precisamente por su vinculación con las transformaciones descritas hasta aquí. Evidentemente casi nadie está en contra de ciertos objetivos como la equivalencia de los títulos o la unificación de los ciclos de enseñanza, la comparabilidad del rendimiento exigido a los alumnos o el establecimiento de criterios y métodos iguales de evaluación y 
de garantía de calidad, la elevación de la empleabilidad de los titulados, etc., por mucho que sea dudoso que esto vaya a aumentar decisivamente la movilidad de docentes y alumnos universitarios o evite que la heterogeneidad siga existiendo debajo de la nomenclatura unificada. Pese a los temores repetidamente expresados, es más que improbable que se produzca una McDonalización de la enseñanza superior (Beck, 2004, 15). El problema surge más bien de que los mencionados objetivos se utilizan para imponer una agenda oculta. Y esta sospecha está más que fundada, pues en la realización de las necesarias reformas que acompañan a la creación del EEES se apela continuamente a todos los lemas que ya hemos señalado, desde la "economía del conocimiento" a las "universidades competitivas", pasando por la "inversión en capital humano" o el reforzamiento de las "ventajas comparativas en el mercado global". El repertorio de estrategias neoliberales que ocupan el escenario de la reforma educativa van desde la estructuración empresarial de las instituciones educativas públicas hasta la presión hacia el establecimiento de un modelo de cheque educativo, en el que universidades públicas y privadas compitan por los consumidores de formación, pasando por la construcción de un mercado formativo para ofertas privadas de servicios educativos. En esta dirección trabajan conjuntamente poderosos lobbies y organizaciones internacionales como la OMC.

El mantenimiento por parte de la Comisión Europea (CE) de un doble objetivo -la reducción del gasto público y la exigencia de mayor gasto en educación- sólo es posible si se recurre, como propone la propia CE, al mecenazgo privado, a la utilización comercial de los resultados de la investigación y al aumento de la "contribución" de los estudiantes (Comisión, 2003, 14-15). Para justificar esto último se suele argumentar con la lógica comercial: si pagan más, exigirán más calidad por lo que pagan (European Commission, 2004a, 8). Por más que en muchos casos la capacidad de pago más que en exigencia de calidad se convierta en una exigencia de titulación. Los intereses en juego son más que evidentes. Pero independientemente de las diferentes posiciones respecto al peso y el equilibrio entre el sector público y el privado, la dirección en la que ambos deben caminar es inequívoca. Se trata de movilizar recursos humanos competitivos y formar enterprising individuals (Jessop, 2002, 165). La reforma educativa del EEES presupone y refuerza la imbricación de las cuestiones de política económica, comercial, laboral y educativa en una determinada dirección. Y la cohesión social, objetivo reconocido de las políticas comunitarias, se presenta como un resultado casi automático del esperable aumento de los índices de crecimiento y de empleo ${ }^{13}$.

13. Resulta sintomático que hasta la conferencia de Berlín (2003) se haya prestado muy poca atención al ámbito de la educación en valores y cuando empieza a hablarse de competitividad y cohesión social, simplemente se yuxtapongan ambos objetivos, sin un análisis en profundidad sobre contradicciones y mediaciones entre ellos (cf. Escámez, OrTega y Martínez, 2005). 
Lo que se exige a las universidades es que diversifiquen y amplíen sus fuentes de financiación y, para ello, adquieran un perfil que las haga atractivas para esas fuentes y, por tanto, más competitivas. En segundo lugar, se les pide que adopten una estructura organizativa según un modelo empresarial (new public management). Los procesos democráticos de decisión y los órganos que los protagonizan aparecen bajo esta perspectiva como lentos e ineficientes. Deberían dejar sitio a cuerpos de dirección tecnocráticos, que permitiesen a las universidades contar "con un proceso eficaz de adopción de decisiones, una capacidad de gestión administrativa y financiera sólida y la posibilidad de vincular la gratificación con los resultados" (Comisión, 2003, 19). Por fin, se recomienda una orientación más enérgica hacia el aprovechamiento mercantil y un mayor influjo económico a través de los public private partnerships, una orientación que permita al conocimiento elaborado en ellas fluir de manera más directa y rápida en la economía. Para esta finalidad el papel decisivo lo juegan las llamadas universidades de elite o centros de excelencia. No hace falta mucha imaginación para representarse el destino de la investigación y la enseñanza críticas no rentabilizables directamente por el mercado.

El proceso de Bolonia y la estrategia de Lisboa van pues de la mano. El primero ha de crear las condiciones estructurales para un mercado europeo de la ciencia y la educación y allanar el camino para una reestructuración neoliberal del ámbito europeo universitario. Para el objetivo de la "empleabilidad" resulta apropiado el cambio que va a sufrir el primer ciclo de la enseñanza superior. El estudio universitario pasará a convertirse para la mayoría de los estudiantes en una formación profesional acorde con las exigencias del mercado de trabajo. El vínculo entre docencia e investigación, que define actualmente la universidad, dejará de tener relevancia para ese primer ciclo, que puede acabar convirtiéndose en una forma de dar una titulación a los que en otro caso interrumpirían los estudios. Pero si se quiere evitar esto y dar una buena cualificación profesional para el mercado de trabajo, las universidades actuales deberían convertirse en escuelas técnicas superiores, lo que plantea la incógnita del destino de las ciencias humanas y sociales.

La forma de cientificidad característica de la universidad parece que pasará al segundo ciclo, al que sólo un reducido número más "capacitado" académicamente tendrá acceso. Sin embargo, la estructura modular que está adoptando este ciclo no permite ser optimista. La iniciativa individual y la libertad de investigación puede verse muy mermada por la tendencia observable en esa estructura a la estandarización y el control, la planificabilidad y comparabilidad. El European Credit Transfer System (ECTS) empieza a producir un desplazamiento en los planes de estudio de las actividades académicas necesarias para alcanzar los objetivos de aprendizaje hacia los rendimientos exigibles a los estudiantes y comparable formalmente. Estos módulos han de ser intercambiables y agrupables de maneras diversas. En el centro de atención de los planes de estudio se colocan el número de créditos acumulable y exigido, la combinabilidad de los módulos y las variantes que permiten. Ante este panorama es probable que la investigación y el tercer ciclo se vayan progresivamente desplazando hacia universidades de elite y centros de excelencia 
que cuenten con fuentes suplementarias de financiación, mientras que la mayoría de universidades se reduzca a funciones de formación y recualificación. También es probable que esto conduzca a una progresiva dualización de los docentes, los estudiantes y los centros.

Estos cambios en el sistema educativo resultan ser congruentes con la transformación del sistema de empleo y de los "vínculos sociales", caracterizados por una creciente individualización y pluralización de los estilos de vida y orientaciones para la acción. Esto no sólo cuestiona las formas tradicionales de regulación del trabajo y de lo social, sino que imprime nuevos contornos a las biografías individuales, a los intereses y a las necesidades de las personas. Un nuevo lema parece presidir la orientación de las biografías individuales independientemente del lugar que se tenga en el sistema productivo: jactúa de modo empresarial! El "yo empresario" se define por la creatividad, la flexibilidad, la responsabilidad individual, la conciencia del riesgo y la orientación al intercambio comercial en todas las áreas de la vida y no sólo en la laboral. La competitividad somete al "yo empresario" al dictado de una permanente optimización de sí mismo, por más que ningún esfuerzo en este sentido sea capaz de desterrar el miedo al fracaso que atrapa su alma (cf. Bröckling, 2007).

El relajamiento actual de las formas tayloristas de organización del trabajo va acompañado de nuevas ofertas de cualificación y participación por parte de los directivos de las empresas a sus plantillas de trabajadores fijos que profundizan la lógica de la identificación y el autocontrol. Lo que del lado de las empresas se denomina corporate identity adquiere del lado de los empleados el carácter de selfmanagement. La personificación de las empresas va de la mano de una reducción del yo a objeto de planificación bajo criterios empresariales. La "personalidad" de directivos y empleados se convierte así en blanco de infinidad de intervenciones que promueven la identificación, estimulan la motivación, impulsan la flexibilidad, etc., por medio del empleo sistemático de técnicas psicológicas (de manipulación) que se presentan como supuestas medidas de "humanización del mundo laboral" o de fomento del "espíritu de grupo".

La competencia global exige una autodisciplinada y completa movilización de toda la persona. La contradicción de intereses entre capital y trabajo queda así encubierta bajo la transformación de los trabajadores en "agentes del capital». Evidentemente esta amigable "flexibilización" ${ }^{14}$ de las relaciones laborales se produce

14. Como señala H. Steinert, "flexibilidad" es el eufemismo habitual para el cambio obligado de residencia o largos trayectos al trabajo, para reciclaje profesional impuesto, para reducida seguridad social en tiempos difíciles o en la vejez, para un trabajo más intensivo en condiciones más desfavorables, para el pequeño empresariado impuesto, dicho lacónicamente, para la aceptación de todas las exigencias que puedan ser solicitadas por parte del capital. Esto quiere decir en las metrópolis retribuciones y condiciones de trabajo peores "a alto nivel", en las periferias explotación hasta el nivel de esclavitud y morir de hambre (STEINER, 2007, 258). 
bajo la presión de una agudizada lucha competitiva entre los trabajadores y bajo el severo dictado de la producción de beneficios. "Entre la formación y el empleo se inserta la frontera llena de riesgos del subempleo" (Beck, 1986, 239). El valor de la formación inicial así como la formación permanente en forma de incontables certificados de cualificación, cursos, seminarios, másteres, etc., nada tiene que ver con una garantía de acceso a un estatus seguro y privilegiado, más bien posee una función selectiva. No aportan gran cosa, pero resultan necesarias para evitar la exclusión. Lo cual tiene un efecto devastador: supone el triunfo de la ideología economicista neoliberal en el plano de la automercantilización de los individuos, que han de estar dispuestos a relativizar sus rasgos personales o incluso a no formar ninguna personalidad en el sentido clásico para adaptarse flexiblemente a las condiciones rápidamente cambiantes del mercado. La jerga dominante lo llama "Oportunismo creativo".

Después del paso a través de las desolaciones del siglo XX sólo ha quedado una apariencia de individuo bajo la exigencia de auto-manipulación. Está llamado a encontrar su "identidad" a través de la identificación con las grandes categorías sociales prescritas por la publicidad y la administración. Un individuo cuya vida interior no merece ningún comentario (en compensación por ello sus rendimientos son medidos regularmente) y cuya sublevación contra las exigencias de la sociedad ha sido desviada hacia el cuidado del perfecto oportunismo (Steinert, 2007, 233).

\section{EDUCAR CONTRA LA BARBARIE, ¿ES POSIBLE?}

Está claro que el análisis realizado hasta aquí no permite ofrecer recetas y menos recetas pedagógicas. Las entrevistas y escritos recogidos en el exitoso volumen que lleva por título Educación para la emancipación (Adorno, 1970) se leen de modo equivocado cuando se espera de ellos indicaciones directas para la praxis educativa. La teoría de la sociedad en que se sustentan parece constatar la imposibilidad de aquello que sería necesario para la emancipación identificada como objetivo de la educación, esto es, una conciencia adecuada de la realidad, es decir, de la dominación persistente, y la voluntad y la energía necesarias para llevar a cabo una transformación radical de la forma de producción capitalista.

Serían necesarios los seres humanos vivos para cambiar la situación petrificada, pero esa se ha introducido tan profundamente en los seres humanos vivos, al precio de su vida y su individuación, que ya casi no parecen capaces de aquella espontaneidad de la que todo depende (Adorno, 1966b, 18).

¿Cómo seguir apostando por el sujeto autónomo, tal como no dejó de hacerlo Adorno, también en sus reflexiones sobre educación? ¿Cómo seguir defendiendo no sólo la necesidad, sino también la posibilidad de una transformación radical de la sociedad? Está fuera de toda duda que la afirmación de que en el proceso de desarrollo capitalista todas las relaciones y necesidades humanas -y por tanto toda la estructura psíquica- adquieren forma mercantil no apagó nunca en 
Adorno el pensamiento de que sería posible algo distinto. Pero si su diagnóstico es correcto, eso otro exige la negación de la forma de mercancía propia del sistema capitalista. La toma de partido por el sujeto es inseparable del esfuerzo por pensar un desarrollo humano y unas relaciones humanas más allá de la forma mercantil de la circulación ampliada del capital. Sin embargo, los seres humanos hoy están mucho más dominados que en fases anteriores por el convencimiento intuitivo de que no puede haber nada distinto a la forma de producción capitalista. La sociedad productora de mercancías es tan absolutamente evidente y carente de alternativas que se ha vuelto "naturaleza segunda".

Adorno entiende que ya el diagnóstico es una forma de romper el círculo (Adorno, 1966b, 18). Éste no está cerrado completamente, pues eso significaría que el diagnóstico mismo sería imposible. En este sentido, se puede afirmar que la posibilidad de cambiar el mundo no ha desaparecido, aunque hayan cambiado las condiciones de dicha posibilidad y lo hayan hecho hasta ensombrecer su horizonte próximo. No hay signos que apunten hacia la constitución de un sujeto global emancipado. Lo cual no imposibilita toda forma de acción. Tan sólo le exige un nivel de reflexibilidad que se haga cargo de dicho ensombrecimiento.

Seguir pensando la posibilidad de principio de un giro hacia el sujeto emancipado ha llevado a tres figuras argumentativas fundamentales de hacerse cargo de la llamada "aporía" del pensamiento adorniano. La primera subraya que el diagnóstico de Adorno se refiere siempre a una tendencia, lo que no sólo deja lugar a la posibilidad del propio diagnóstico, sino también deja abierta la posibilidad de una alternativa (cf. Claussen, 1988, 28 y ss.). La segunda apunta a la imposibilidad de principio de una completa integración coactiva. La propia coacción frustra permanentemente su objetivo e instaura la distancia que posibilita la crítica y la acción transformadora, aunque su existencia real no sea garantizable a priori (cf. Zamora, 2004, 209 y ss.). La tercera apunta a la doble determinación de la génesis del sujeto. Existe una dimensión del yo que se sustrae a la determinación psicológica, a la que queda restringida el diagnóstico adorniano. Ésta sería relevante en relación a las condiciones empíricas de realización de la emancipación, pero la emancipación misma es un acto de libertad y como tal responde a la determinación racional del yo. Adorno nunca habría renunciado a la distinción entre génesis y validez (Weyland, 2001, 147 y ss.).

A estas figuras argumentativas que pretenden asegurar la posibilidad de principio de una conciencia crítica y una praxis emancipadora quizás habría que añadir el esfuerzo de señalar las posibles formas actuales de su realización (Becker y Brakemaier, 2004). Dicha tarea no es principalmente un asunto pedagógico. Tiene que ver con la existencia de movimientos emancipadores y con su capacidad de lucha. En este sentido resultan esperanzadores los esfuerzos por conectar sin renuncias teóricas o políticas los más recientes movimientos emancipadores con la teoría crítica de la sociedad de Adorno (Holloway, Matamoros y Tischler, 2007). Si la educación quiere aportar algo en esta lucha tiene que partir de una sociedad y una política organizadas de hecho bajo el principio de dominación y estabilizadas 
por las agencias, entre ellas la propia educación, que sirven a esa dominación, analizándolas desde la perspectiva de los sujetos que las padecen.

La situación de dominación y la posible liberación sólo se hacen accesibles bajo una perspectiva de crítica ideológica, por medio del análisis de las contradicciones con las que uno se encuentra, por medio de la memoria de promesas históricas inscritas en dichas contradicciones e incumplidas, por medio de experiencias que siempre pueden hacerse en el mundo administrado burocráticamente y troquelado por la forma de la mercancía ${ }^{15}$. Esto exige un plus de reflexividad que empieza en la autocrítica de la educación y su imbricación en la totalidad antagonista en el desarrollo de la tarea misma de educar. Es necesario atender a la imbricación de las instituciones y prácticas pedagógicas con las estructuras sociales que impiden la emancipación. Una pedagogía que no reflexione autocríticamente sobre su lugar y función en la reproducción de dichas estructuras, que no perciba cómo la organización social genera y mantiene la heteronomía también a través de las instituciones pedagógicas llamadas a combatirla, no hará sino contribuir a la perpetuación de la barbarie (cf. Soares Zuin, 1999, 117 y ss.).

Educar en este sentido supone una reflexión de todos los que participan en esta actividad sobre la coacción que sufren a integrarse de modo total, sobre las formas sutiles de autoridad y dominación mediadas por el capital, sobre su propio lugar en la totalidad antagonista, sobre la propia función en lo existente, que se ejerce de manera inconsciente y automática. Educación sería la tarea de ayudar a cuestionar esa función, la coacción social y la dominación, a negar la reducción de los individuos a categorías económicas, a desenterrar y formular por medio de un trabajo crítico negativo los propios intereses y necesidades, en los que poder reconocerse como fines en sí, evitando la falsa apariencia de una supuesta autonomía que todavía está por realizar. Educar así sería luchar contra la ilusión de una vida lograda en medio de sociedad falsa. "El individuo sólo sobrevive hoy", se atrevió a decir Adorno, "como centro de fuerza de la resistencia” (Adorno, 1970, 119).

15. Sobre el poder educativo del pensamiento autorreflexivo, cf. A. A. Soares Zuin, B. Pucci y N. Ramos-De-Oliveira, 2000, 109 y ss. No conviene olvidar el papel que juega el sufrimiento producido por la coacción social (sufrimiento que siempre posee un sustrato somático) en esa autorreflexión que posibilita una experiencia en sentido enfático (Zamora, 2004, 249 y ss.), así como la importancia para la ecuación moral de los sentimientos involucrados en esa experiencia (Ortega y Escámez, 2006; Ortega, 2006). 


\section{Bibliografía}

Adorno, Th. W. (1970-1986) Gesammelte Schriften, 20 tomos, ed. por R. Tiedemann con la colaboración de G. Adorno, S. Buck-Morss y K. Schulz. Frankfurt a. M., Suhrkamp (cit. $G S$, tomo y páginas). Las obras de Adorno se citarán por la fecha de su primera publicación, las lecciones por la fecha en que fueron impartidas y los escritos publicados póstumamente por la fecha de su publicación, indicando después del título la fecha en que fue redactado.

- (1938) Über den Fetischcharakter in der Musik, GS 14, 14-50.

- (1942) Reflexionen zur Klassentheorie, GS 8, 373-391.

- (1947, con Horkheimer, M.) Dialektik der Aufklärung, GS 3.

- (1951a) Minima moralia, GS 4.

- (1951b) Kulturkritik und Gesellschaft, GS 11.1, 11-30.

- (1952, con Horkheimer, M.) Vorurteil und Charakter, GS 9, 360-373.

- (1953) Über Technik und Humanismus, GS 20.1, 310-317.

- (1957) Soziologie und empirische Forschung, GS 8, 196-216.

- (1959a) Theorie der Halbbildung, GS 8, 93-121.

- (1959b) Aberglaube aus zweiter Hand, GS 8, 147-176.

- (1960) Kultur und Verwaltung, GS 8, 122-146.

- (1961) Meinung Wahn Gesellschaft, GS 10.2, 573-594.

- (1962) Notiz über Geisteswissenschaft und Bildung, GS 10.2, 495-498.

- (1963) Drei Studien zu Hegel, GS 5, 247-361.

- (1964/65) Zur Lehre von der Geschichte und der Freiheit, ed. por R. Tiedemann, en Nachgelassene Schriften, t. 13, Frankfurt a. M., Suhrkamp, 2001.

- (1965) Tabus über dem Lehrberuf, GS 10.2, 656-673.

- (1966a) Negative Dialektik, GS 6.

- (1966b) Gesellschaft, GS 8, 9-19.

- (1967a) Erziehung nach Auschwitz, GS 10.2, 664-690.

- (1967b) Résumé über Kulturindustrie, GS 10.1, 337-345.

- (1968) Einleitung in die Soziologie, ed. por Ch. GöDDE, en Nachgelassene Schriften, t. 15. Frankfurt a. M., Suhrkamp, 1993.

- (1969a) Einleitung zum "Positivismusstreit in der deutschen Soziologie", GS 8, 280-353.

- (1969b) Spätkapitalismus oder Industriegesellschaft?, GS 8, 7-412.

- (1970a) Ästhetische Theorie, GS 7.

- (1970b) Erziehung zur Mündigkeit. Vorträge und Gespräche mit Hellmut Becker 19591969, ed. por G. Kadelbach. Frankfurt a. M., Suhkamp.

- (1980) Schema der Kulturindustrie (1942), GS 3, 299-335.

Beск, U. (1986) Risikogesellschaft. Auf dem Weg in eine andere Moderne. Frankfurt a. M., Suhrkamp.

— (2004) Vorwärts zu "Humboldt 2", Die Zeit, n. ${ }^{\circ}$ 47, 11 nov., 15.

Becker, J. y Brakemaier, H. (eds.) (2004) Vereinigung freier Individuen. Kritik der Tauschgesellschaft und gesellschaftliches Gesamtsubjekt bei Theodor W. Adorno. Hamburgo, VSA.

BeHrens, R. (2004) Verstummen über Adorno. Laatzen, Wehrhahn.

Benjamin, W. (1940) Über den Begriff der Geschichte, en Tiedemann, R. y Schweppenhä̈user, H. et al. (eds.). Gesammelte Schriften, t. 1. 2 (3. ${ }^{a}$ ed.). Frankfurt a. M., Suhrkamp, 1990, 691-704. 
TH. W. ADORNO: APORTACIONES PARA UNA TEORÍA CRÍTICA DE LA EDUCACIÓN

Blankertz, H. (1985) Berufsbildung und Utilitarismus. Problemgeschichtliche Untersuchungen. Weinheim/München, Juventa.

Bourdieu, P. (1988) La distinción. Criterios y bases sociales del gusto. Madrid, Taurus (orig. fra. 1979).

BröCKLING, U. (2007) Das unternehmerische Selbst. Soziologie einer Subjektivierungsform. Frankfurt a. M., Suhrkamp.

Claussen, D. (1988) Unterm Konformitätszwang: zum Verhältnis von kritischer Theorie und Psychoanalyse. Bremen, Wassmann.

- (1990) Die Aktualität der Kulturkritik Adornos, en Hager, F. y Pfütze, H. (eds.). Das unerhört Moderne. Berliner Adorno-Tagung. Lüneburg, zu Klampen, 134-150.

- (1995) Konformistische Identität. Zur Rolle der Sozialpsychologie in der Kritischen Theorie, en Schweppenhäuser, G. (ed.). Soziologie im Spätkapitalismus. Zur Gesellschaftstheorie Theodor W. Adornos. Darmstadt, WBG, 27-40.

Comisión de las Comunidades Europeas (2003) El papel de las universidades en la Europa del conocimiento, COM (2003) 58 final. 5 de febrero. http://eur-lex.europa.eu/LexUriServ/ LexUriServ.do?uri=COM:2003:0058:FIN:ES:PDF.

DuARTE, R. (2003a) Teoria crítica da indústria cultural. Belo Horizonte, Editora UFMG.

- (2003b) Esquematismo e semiformação, Educ. Soc., Campinas, vol. 24, n. ${ }^{\circ}$ 83, agosto, 441-457.

Escámez, J.; Ortega, P. y Martínez, M. (2005) Los valores de la educación en el Espacio Europeo de la Enseñanza Superior, en Esteban Chapapría, V. (ed.). El Espacio Europeo de Educación Superior. Valencia, UPV (Universidad Politécnica de Valencia), 165-198.

European Commission-Directorate General Education and Culture (2004a) Implementation of "Education \& Training 2010". Work Programme: Working Group E "Making the best use of resources", Progress Report, December. http://ec.europa.eu/education/policies/2010/doc/best2004.pdf.

GÖRG, Ch. (2004) Zwischen Tauschgesellschaft und Wertgesetz Adornos Gesellschaftskritik und die heutige Globalisierungsdiskussion, en Becker, J. y BraKemaier, H. (eds.). Vereinigung freier Individuen. Kritik der Tauschgesellschaft und gesellschaftliches Gesamtsubjekt bei Theodor W. Adorno. Hamburgo, VSA, 247-258.

Hirsch, J. y Roth, R. (1986) Das neue Gesicht des Kapitalismus. Vom Fordismus zum PostFordismus. Hamburg, VSA.

Holloway, J.; Matamoros, F. y Tischler, S. (comps.) (2007) Negatividad y revolución. Theodor W. Adorno y la política. Buenos Aires/México, Herramienta/Univ. de Puebla.

Jessop, B. (2002) The Future of Capitalist State. Cambridge, Polity Press.

Institut für Sozialforschung (ed.) (1983). Soziologische Exkurse. Nach Vorträgen und Diskussionen. Frankfurt a. M., Europäische Verl.-Anst.

Kellner, D. (1983) Kulturindustrie und Massenkommunikation. Die Kritische Theorie und ihre Folgen, en Bonss, W. y Honneth, A. (eds.). Sozialforschung als Kritik. Frankfurt a. M., Suhrkamp, 482-515.

KöNIG, H.-D. (2000) Adornos psychoanalytische Kulturkritik und die Tiefenhermeneutik. Zugleich eine Sekundäranalyse des 24. Aphorismus der Minima Moralia, Zeitschrift für kritische Theorie, 10, 7-26.

Liessmann, K. P. (2006) Theorie der Unbildung. Die Irrtümer der Wissensgesellschaft. Wien, Paul Zsolnay.

MaAr, W. L. (2003) Adorno, semiformação e educação, Educ. Soc., Campinas, vol. 24, n. ${ }^{\circ}$ 83, agosto, 459-476. 
Marx, K. (1974) Grundrisse der Kritik der politischen Ökonomie. Berlín, Dietz.

MeYer, L. (2005) Absoluter Wert und allgemeiner Wille. Zur Selbstbegründung dialektischer Gesellschaftstheorie. Bielefeld, transcript.

Ortega Ruiz, P. (2006) Sentimientos y moral en Horkheimer, Adorno y Levinas, Revista española de pedagogia, vol. 64, n. ${ }^{\circ} 235,503-524$.

Ortega Ruiz, P. y Escámez Sánchez, J. (2006) Los sentimientos en la educación moral, Teoría de la educación, n. ${ }^{\circ} 18,109-134$

Peukert, H. (1991) "Erziehung nach Auschwitz" - eine überholte Situationsdefinition? Zum Verhältnis von Kritischer Theorie und Erziehungswissenschaft, en Hoffmann, D. (ed.). Bilanz der Paradigmendiskussion in der Erziehungswissenschaft. Weinheim, Deutscher Studien Verlag, 127-140.

Sanz Fernández, F. (2005) El Espacio Europeo de Educación Superior: documentos para una (o varias) teorías de la educación, Teoría de la educación, n. ${ }^{\circ}$ 17, 255-285.

Seet, M. (1987) Dialektik des Erhabenen. Kommentare zur «ästhetischen Barbarei heute», en RejJen, W. V. y Schmid Noerr, G. (eds.). Vierzig Jahre Flaschenpost: 'Dialektik der Aufklärung' 1947 bis 1987. Frankfurt a. M., Fischer, 11-40.

Soares Zuin, A. A. (1999) Indústria cultural e educação. O novo canto da sereia. Campinas, Autores Associados.

Soares Zuin, A. A.; Pucci, B. y Ramos-De-Oliveira, N. (2000) Adorno. O poder educativo do pensamiento crítico. Petrópolis, Vozes.

Stapelfeldt, G. (2007) Der Aufbruch des konformistischen Geistes. Thesen zur Kritik der neoliberalen Universität. Hamburg, Dr. Kovac.

Steinert, H. (1998) Kulturindustrie. Münster, Westfälisches Dampfboot.

- (2007) Das Verhängnis der Gesellschaft und das Glück der Erkenntnis. Dialektik der Aufklärung als Forschungsprogramm. Münster, Westfälisches Dampfboot.

Weyand, J. (2001) Adornos Kritische Theorie des Subjekts. Lüneburg, zu Klampen.

Zamora, J. A. (2004) Th. W. Adorno: Pensar contra la barbarie. Madrid, Trotta.

- (2007) El enigma de la docilidad: Teoría de la sociedad y psicoanálisis en Th. W. Adorno, en Савот, M. (ed.). El pensamiento de Th. W. Adorno. Balance y perspectivas. Palma, Universitat de les Illes Balears, 27-42.

- (2008) Educação depois de Auschwitz, en Moreira, A. da S.; Pucci, B. y Zamora, J. A. Adorno, Educação y Religião. Goiânia, UCG, 11-27.

Zuckermann, M. (2000) Aspekte "hoher" und "niedriger" Kultur. Zur anachronistischen Aktualität Adornos, Zeitschrift für kritische Theorie, 10, 89-106. 